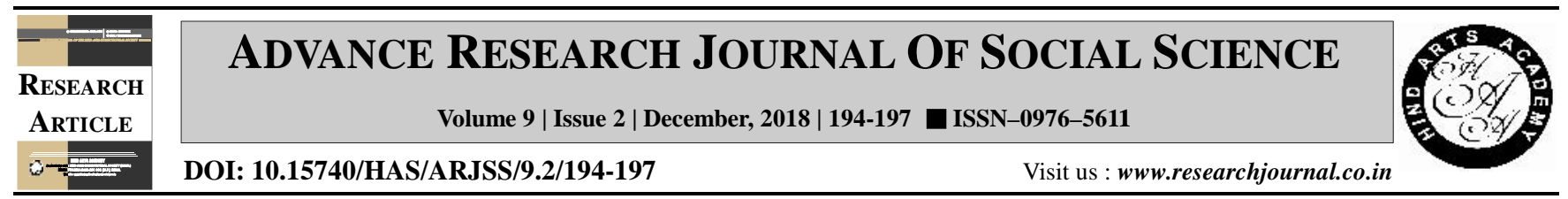

\title{
Enhancing the parents-child communication skills providing favourable home environment in Haryana state
}

Pinki Rani

Department of Human Development and Family Studies, I.C. Collage of Home Science, C.C.S. Haryana Agricultural Univesity, Hisar (Haryana) India

\section{ARTICLE INFO :}

Received : 12.04 .2018

Revised : 12.11 .2018

Accepted : 15.11 .2018

\section{KEY WORDS :}

Home environment, Parents-child interaction, Emotional climate, Learning materials, Family companionship, Communication skill

HOW TO CITE THIS ARTICLE : Rani, Pinki (2018). Enhancing the parents-child communication skills providing favourable home environment in Haryana state. Adv. Res. J. Soc. Sci., 9 (2) : 194-197, DOI: 10.15740/HAS/ ARJSS/9.2/194-197.

Copyright@2018 : Hind Agri -

Horticultural Society

\begin{abstract}
Home environment provided by the parents, parental behaviour, their interaction with child and related factors tend to influence the cognitive development and socialization of children. The present study was conducted purposively in Hisar district of Haryana state. From Hisar district two areas were selected i.e., urban and rural. The sample consist 100 girls between the age group of 7-8 years and their parents (both mother and father). 50 girls and their parents were selected randomly from Hisar city and 50 girls and their parents were selected randomly from rural area. A total of 50 boys between the age group of 7 to 8 years with both of their parents were selected randomly from each location. Hence, the total sample was 600 including (200 children and 400 their parents). Home observation for measurement of the environment (HOME) by Bradley and Caldwell (1984) and Parenting Style and Dimensions Questionnaire (PSDQ) by Robinson et al. (1995) were used to measure home environment and Parenting Style and Dimensions Questionnaire (PSDQ) by Robinson et al. (1995) was used to measure parenting style i.e. authoritative, authoritarian and permissive. Vineland adaptive behaviour scale by Sparrow et al. (1984) used to measure the communication skill of children. Result revealed that aspect of home environment responsivity, encouragement of maturity, learning material and opportunities, enrichment were significantly associated with adaptive behaviour. Emotional climate, learning material and opportunities, Family integration, family companionship, physical environment and composite home environment were non-significantly associated with adaptive behaviour.
\end{abstract}

